\title{
Evaluation of the Time Period for Which Real-Time Polymerase Chain Reaction Detects Dead Bacteria
}

\author{
HYONMIN CHOE, YUTAKA INABA, NAOMI KOBAYASHI, YUSHI MIYAMAE, HIROYUKI IKE, \\ HIROSHI FUJIMAKI, TARO TEZUKA, YASUHIDE HIRATA and TOMOYUKI SAITO
}

Yokohama City University School of Medicine, Department of Orthopaedic Surgery, Yokohama, Japan

Submitted 12 July 2013, revised 27 May 2014, accepted 15 September 2014

\begin{abstract}
Real-time polymerase chain reaction (PCR) is currently widely used for the diagnosis of infections. We evaluated the time after treatment during which real-time PCR can detect dead bacteria. The presence of bacterial DNA was identified by real-time PCR through methicillinresistant Staphylococcus (MRS)-PCR and universal PCR. Methicillin-resistant Staphylococcus aureus (MRSA), Staphylococcus epidermidis, and Escherichia coli were each killed with alcohol, antibiotics, or heat treatment in vitro. The detection periods of MRS-PCR for MRSA treated by alcohol, vancomycin, linezolid, and heat were found to be less than $16,8,12$, and 8 weeks, respectively. The detection period of universal PCR for S. epidermidis treated by alcohol, cefazolin, and heat was less than 20, 20, and 4 weeks, whereas that for $E$. coli was 8 , 20 , and 4 weeks, respectively. The presence of detectable bacterial DNA in infected arthroplasty patients before and after successful treatment was also assessed by MRS- and universal PCR. MRS-PCR was positive in 6 patients before treatment and all became negative after a mean interval of 20.8 weeks (95\% confidential interval, 13.2 to 33.7 ) after treatment. Universal PCR detected remnant bacterial DNA in 4 patients at a mean of 15.2 weeks (95\% CI, 12.4 to 18.0) after treatment and was negative in 7 patients at a mean of 17.3 weeks (95\% CI, 10.6 to 24.0) after treatment. Our studies revealed that real-time PCR detects dead bacteria for several weeks, but this capability decreases with time and is likely lost by 20 weeks after treatment.
\end{abstract}

Key words: dead bacterial DNA, MRS-PCR, real-time PCR, universal PCR

\section{Introduction}

Clinically infected but culture negative cases are difficult to make definitive diagnoses of infection. Although the conventional laboratory method of determining bacterial cell viability by visible colonies on a suitable solid medium is a universal method for the determination of the causative organism, it is unreliable for the diagnosis of viable but non-culturable (VBNC) bacterial infection (Trevors, 2011; Trevors, 2012). Elevated C-reactive protein (CRP) levels and erythrocyte sedimentation rate (ESR) are recognized as good indicators of infections (Sanzen et al., 1989); these are non-specific markers for the diagnosis of infection. Several novel diagnostic tools based on real-time PCR have been developed recently and used for the diagnosis of infections (Choe et al., 2013, Moojen et al., 2010, Morre et al., 1998, Nilsson et al., 2008). It is a rapid and sensitive method (Kobayashi et al., 2009), however, one major concern is that PCR can detect not only live but also dead bacteria (Keer et al., 2003, McKillip et al., 1999, Workowski et al., 1993).

Appropriate antibiotic therapy is usually useful for eradicating bacterial infection, however, some patients may develop a VBNC bacterial condition when the microorganisms propagate in biofilms that facilitate bacterial survival despite antibiotic treatment (Trevors, 2011). Consequently, it is occasionally difficult to judge the infection status in antibiotic-initiated patients with PCR-positive but culture-negative results. In these patients, it is unclear whether PCR detects remnant dead bacterial DNA, even in patients after the infection has been successfully treated or if the positive PCR reflects viable bacteria in a VBNC condition (McKillip et al., 1999, Workowski et al., 1993). The exact period for which real-time PCR can detect remnant bacterial DNA from dead bacteria is therefore important, but has not been well evaluated. In the present study, we addressed the following 2 questions: the time period for which real-time PCR can continue to

\footnotetext{
* Corresponding author: H. Choe, Department of Orthopedic Surgery, Yokohama City University, Yokohama, Japan; e-mail: hyonmin@ hotmail.com
} 
detect killed bacteria and whether the capability of realtime PCR for determination of dead bacterial DNA will decrease overtime.

\section{Experimental}

\section{Materials and Methods}

Bacterial Strains and Growth Conditions in vitro. Methicillin-resistant Staphylococcus aureus (MRSA) (a clinically isolated strain), Staphylococcus epidermidis (ATCC [America Type Culture Collection] 12228), and Escherichia coli (ATCC 23231) were tested in this study. Each bacterial strain was grown for $24 \mathrm{~h}$ at $37^{\circ} \mathrm{C}$ in a Luria-Bertani (LB, Difco Laboratories, Detroit, MI) agar plate before analysis. Single colony of MRSA, S. epidermidis, and E. coli were isolated and inoculated into $20 \mathrm{ml}$ of $\mathrm{LB}$ broth. LB broth was incubated at $37^{\circ} \mathrm{C}$ and $300 \mu \mathrm{l}$ of overnight culture were incubated in the $30 \mathrm{ml}$ of LB broth for 3 hours. Bacterial suspensions of each strain were adjusted to $0.5 \mathrm{McF}$ arland standards.

Methods of treatment in vitro. Each strain was separately treated using (1) alcohol, (2) antibiotics, and (3) heat, and 5 samples were prepared for each treatment method. The reaction conditions were as follows: (1) Alcohol, all strains were adjusted to $1 \times 10^{5} \mathrm{CFU} / \mathrm{ml}$ using 95\% ethanol (final concentration, 90\%) and 0.9\% saline; (2) Antibiotics, MRSA was adjusted to $1 \times 10^{5}$ $\mathrm{CFU} / \mathrm{ml}$ using $0.9 \%$ saline. Vancomycin (VCM) or linezolid (LZD) were added to produce a final concentration of $100 \mu \mathrm{g} / \mathrm{ml}$. S. epidermidis and E. coli were adjusted to $1 \times 10^{5} \mathrm{CFU} / \mathrm{ml}$ using $0.9 \%$ saline. Cefazolin (CEZ) was added to a final concentration of $100 \mu \mathrm{g} / \mathrm{ml}$. The minimum inhibitory concentration (MIC) of each strain was determined using MIC determination kit (Micro Scan; Dade Behring Inc, Deerfield, IL), and MIC of these antibacterial drugs for each bacterium were confirmed to be below $2 \mu \mathrm{g} / \mathrm{ml}$ (3). Heat shock, all strains were adjusted to $1 \times 10^{5} \mathrm{CFU} / \mathrm{ml}$ using $0.9 \%$ saline and were treated at $100^{\circ} \mathrm{C}$ for $10 \mathrm{~min}$.

After each treatment procedure, the bacterial suspensions were maintained at $37^{\circ} \mathrm{C}$ for 2 days and for 1 , $4,8,12,16$, and 20 weeks. All of the resulting bacterial suspensions were proceeded for microbiological culture and real-time PCR analysis.

Microbiological culture for treated bacteria in vitro. $100 \mu \mathrm{L}$ of each culture sample was grown in $20 \mathrm{ml}$ of LB broth for 48 hours. Subsequently, the treated state of the bacteria was confirmed by growing $100 \mu \mathrm{L}$ aliquots of these bacterial suspensions in either MRSspecific agar for the MRSA strain or LB agar for the S. epidermidis and E. coli strains.

DNA Extraction and Real-Time PCR. For DNA extractions, $200 \mu \mathrm{L}$ aliquots of solutions were taken from each sample. DNA extractions were performed using a Bio Robot EZ1 DNA investigator kit with a Bio Robot EZ1 (Qiagen Inc., Valencia, CA) in accordance with the manufacturer's instructions. We used a Light Cycler system (Roche Diagnostics, Mannheim, Germany) to perform the real-time PCR assay. Two different primer and probe sets were used: a commercially available MRSA specific detection kit (Roche Diagnostics, Mannheim, Germany) targeting the $m e c A$ gene (MRS-PCR) and a set of primers (forward: 5'-CAAACAGGATTAGA.TACCCTG-3' and reverse: 5'-GGTAAGGTTCTTCGCG-3') and hybridization probes designed for broad range detection that targeted a part of the 16S rRNA gene (universal PCR) (Choe et al., 2013, Kobayashi et al., 2006, Kobayashi et al., 2009). MRS-PCR was used for the solutions containing treated MRSA and universal PCR were used for the solutions with treated S. epidermidis and E. coli. We placed $5 \mu \mathrm{L}$ of DNA extract into a final reaction volume of $20 \mu \mathrm{L}$ for each tube. The cycling conditions were $95^{\circ} \mathrm{C}$ for $10 \mathrm{~min}$, followed by 45 cycles of denaturation at $95^{\circ} \mathrm{C}$ for $10 \mathrm{~s}$, annealing at $55^{\circ} \mathrm{C}$ for $10 \mathrm{~s}$, and extension at $72^{\circ} \mathrm{C}$ for $12 \mathrm{~s}$. The amplified products were then quantified using the LightCycler software. The differences between the threshold cycles (Ct) for the negative control (sterile water) and the treated bacteria were calculated using the formula:

$$
\begin{aligned}
& \Delta \mathrm{Ct}=\mathrm{Ct}_{\text {negative control }}-\mathrm{Ct}_{\text {treated bacteria in universal PCR results }} \\
& \Delta \mathrm{Ct}>2.0
\end{aligned}
$$

cycles was defined as a positive result in universal PCR (Miyamae et al., 2012).

Clinical cases The current clinical study was approved by our institutional review board. Samples were harvested from total hip or knee arthroplasty patients who were diagnosed with an infection by a positive result in microbiological culture or histopathology. A histopathological diagnosis of infection was made when the infiltration of $\geq 10$ neutrophils per high-power visual field $(\times 400)$ was confirmed (Lonner et al., 1996; Tsaras et al., 2012). All patients underwent the two-stage revision surgery that consisted of the first surgery (surgical debridement and implant removal), an interval period with antibacterial treatment, and a second surgery (revision arthroplasty). At the time of first and second surgery, tissue samples were harvested and underwent MRS- and/or universal PCR analysis. Eradication of bacteria was confirmed in all patients by negative results in microbiological culture and histopathology at the time of second surgery and the absence of clinical and radiographic evidence of infection. All patients completed at least one year of follow-up period after second surgery. Real-time PCR results obtained for each patient before and after treatment (at the time of first surgery and second surgery) were compared.

Statistical analysis. Statistical significance of difference among in vitro longitudinal data of $\mathrm{Ct}$ val- 
ues in MRS-PCR or $\triangle \mathrm{Ct}$ values in universal PCR at each time point after treatment were determined by repeated measures analysis of variance (ANOVA) followed by Bonferroni t-test or by Friedman repeatedmeasures ANOVA on ranks followed by Scheffe test when assumptions of normality or homogeneity of variances were not verified. Statistical significance of difference between clinical samples harvested at $1^{\text {st }}$ and $2^{\text {nd }}$ surgery of $\mathrm{Ct}$ values in MRS-PCR or $\Delta \mathrm{Ct}$ values in universal PCR were determined by paired $t$ test or Wilcoxon signed ranks test when the data was not normally distributed. All tests were reported as significant differences if $\mathrm{p}$ value was less than 0.05 .

\section{Results}

In our in vitro study, all cultures containing treated MRSA, S. epidermidis, and E. coli showed no growth of colonies after 1week. MRS-PCR results were positive in all 5 samples for MRSA at 2 days after each treatment (Figure 1-A). The mean Ct values of MRS-PCR for MRSA at 2 days after treatment were significantly lower than those at 1 week and 4 weeks for each treat-
Table I

Time period that real-time PCR proved negative

\begin{tabular}{|l|l|c|c|}
\hline \multirow{2}{*}{} & \multirow{2}{*}{$\begin{array}{c}\text { MRS-PCR } \\
\text { MRSA }\end{array}$} & \multicolumn{2}{|c|}{ Universal PCR } \\
\cline { 3 - 4 } & & S. epidermidis & E. coli \\
\hline Alcohol & 16 weeks & 20 weeks & 8 weeks \\
\hline Antibiotic & VCM: 8 weeks & 20 weeks & 20 weeks \\
& LZD: 12 weeks & & \\
\hline Heat & 8 weeks & 4 weeks & 4 weeks \\
\hline
\end{tabular}

ment (Figure 1-B). Heat- and VCM-treated MRSA were not detected by MRS-PCR at 8 weeks after treatment. LZD-treated and alcohol-treated MRSA were all negative in MRS-PCR by 12 weeks and 16 weeks, respectively (Table I). Universal PCR results were positive in all 5 samples for S. epidermidis and E. coli at 2 days after each treatment. The mean $\Delta \mathrm{Ct}$ values of $S$. epidermidis at 2 days after alcohol-, CEZ-, and heat-treatment were $4.5,4.6$, and 4.0, respectively. The $\Delta \mathrm{Ct}$ values of S. epidermidis showed a gradual decrease up to the 4 -week time point. The mean $\Delta \mathrm{Ct}$ values of the CEZ- and heat-treated S. epidermidis were significantly higher at 2 days than at any other time point and that value of the alcohol-treated S. epidermidis was significantly higher

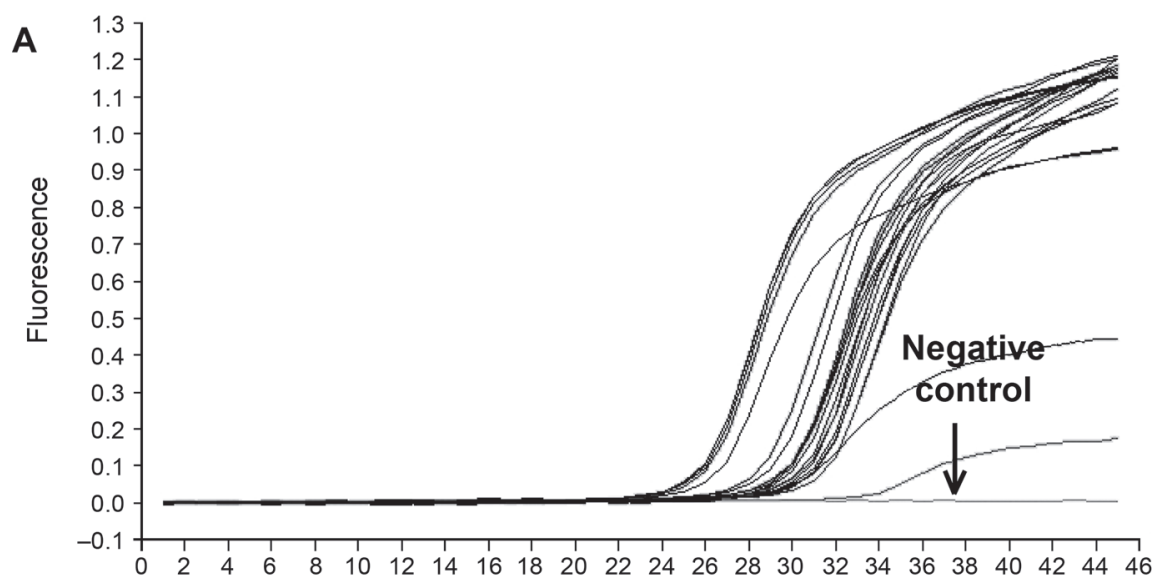

B

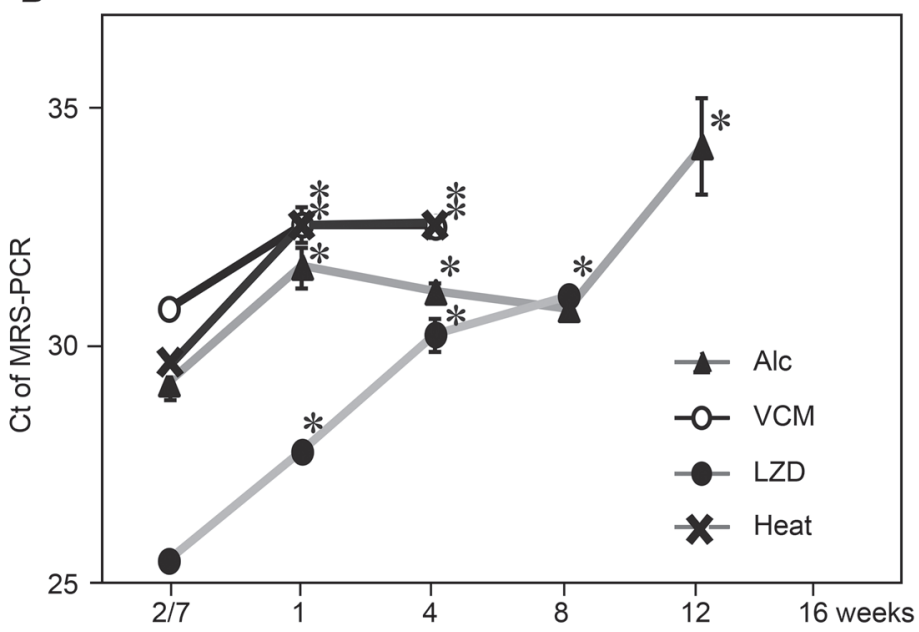

Fig. 1. Threshold cycle (Ct) values of methicillin-resistant Staphylococcus (MRS)-PCR for treated methicillin-resistant Staphylococcus aureus (MRSA)increased overtime after each treatment in vitro

MRSA were processed for MRS-PCR analysis at indicated time points after the treatments. (A) At 48 hours after each treatment, all samples showed positive results in MRS-PCR excluding the negative control (sterile water). (B) The mean Ct values of MRSA at 2 days after each treatment gradually increased over time. As a result, the detectable period of MRS-PCR for MRSA treated by alcohol (Alc), vancomycin (VCM), linezolid (LZD), and heat were less than $16,8,12$, and 8 weeks, respectively. All experiments were conducted with 5 samples. *'s denotes $\mathrm{p}<0.05$ and ${ }^{* *}$ 's denotes $\mathrm{p}<0.01$ in repeated measures ANOVA followed by Bonferroni t-test. 

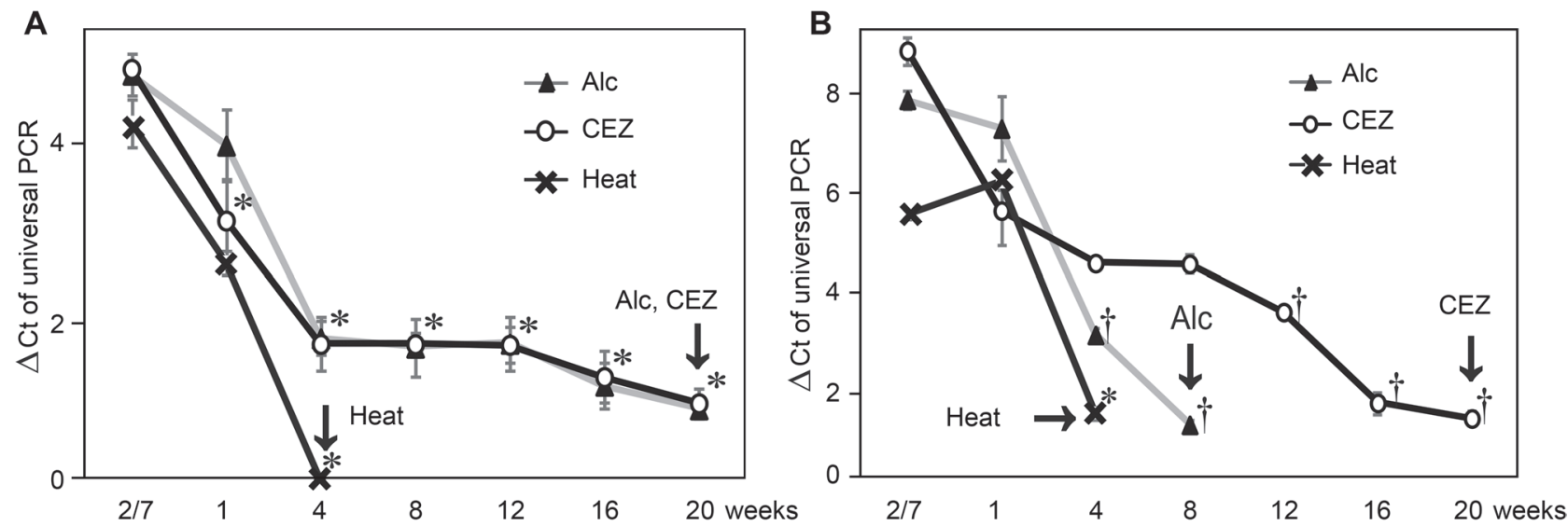

Fig. 2. Mean delta threshold cycle $(\Delta \mathrm{Ct})$ values of universal PCR for treated Staphylococcus epidermidis (S. epidermidis) and Escherichia coli (E. coli) decreased overtime after treatment in vitro

S. epidermidis and E. coli were processed for universal PCR analysis at the indicated time points after the treatments. The differences of threshold cycles for the sterile water $(\Delta \mathrm{Ct})$ were noted and $\Delta \mathrm{Ct}>2.0$ was defined as a positive in universal PCR. (A) The mean $\Delta \mathrm{Ct}$ of S. epidermidis at 2 days after each treatment gradually decreased overtime and universal PCR for S. epidermidis treated by alcohol, cefazolin (CEZ), and heat showed negative results at 20,20, and 4 weeks whereas viable E. coli were detected less than 8,20, and 4 weeks, respectively. All experiments were conducted with 5 samples. Arrows point the week which real-time PCR showed negative in all samples. *'s denotes $\mathrm{P}<0.05$ in repeated measures ANOVA followed by Bonferroni t-test. $\dagger$ 's denoted $\mathrm{P}<0.05$ in Friedman repeated-measures ANOVA on ranks followed by Scheffe test.

at 2 days than at 4 weeks (Figure 2-A). Universal PCR results for alcohol-, CEZ-, heat-treated S. epidermidis were negative in all 5 samples by 20,20, and 4 weeks, respectively (Table I). The mean $\Delta \mathrm{Ct}$ values of $E$. coli at 2 days after alcohol-, CEZ-, and heat-treatment were 7.6, 8.6, and 5.3, respectively. The mean $\Delta \mathrm{Ct}$ value of the CEZ-treated E. coli was significantly higher at 2 days than at 12 weeks. The mean $\Delta \mathrm{Ct}$ values for the alcoholor heat-treated $E$. coli were significantly higher at 2 days than at 4 weeks (Figure 2-B). The $\Delta \mathrm{Ct}$ values of $E$. coli decreased and all universal PCR results were negative at 8 weeks, 20 weeks, and 4 weeks after alcohol-, CEZ-, and heat-treatment, respectively (Table I).
In clinical cases, MRS-PCR was positive in 6 patients with mean $\mathrm{Ct}$ values of 31.4 at the time of first surgery. All 6 patients were negative at the time of second surgery after a mean 20.8 weeks ( $95 \%$ confidential interval, 13.2 to 33.7) of interval period (Figure 3-A). Universal PCR, performed in 11 patients, decreased from a mean $\Delta \mathrm{Ct}$ value of 4.9 at the time of first surgery to 1.8 at the time of second surgery after a mean 16.5 weeks interval (Figure 3-B). Universal PCR detected remnant bacterial DNA in 4 out of 11 patients at the time of second surgery after a mean interval of 15.2 weeks ( $95 \%$ CI, 12.4 to 18.0) and was negative in 7 patients after a mean interval of 17.3 weeks (95\% CI, 10.6 to 24.0 ). In any cases
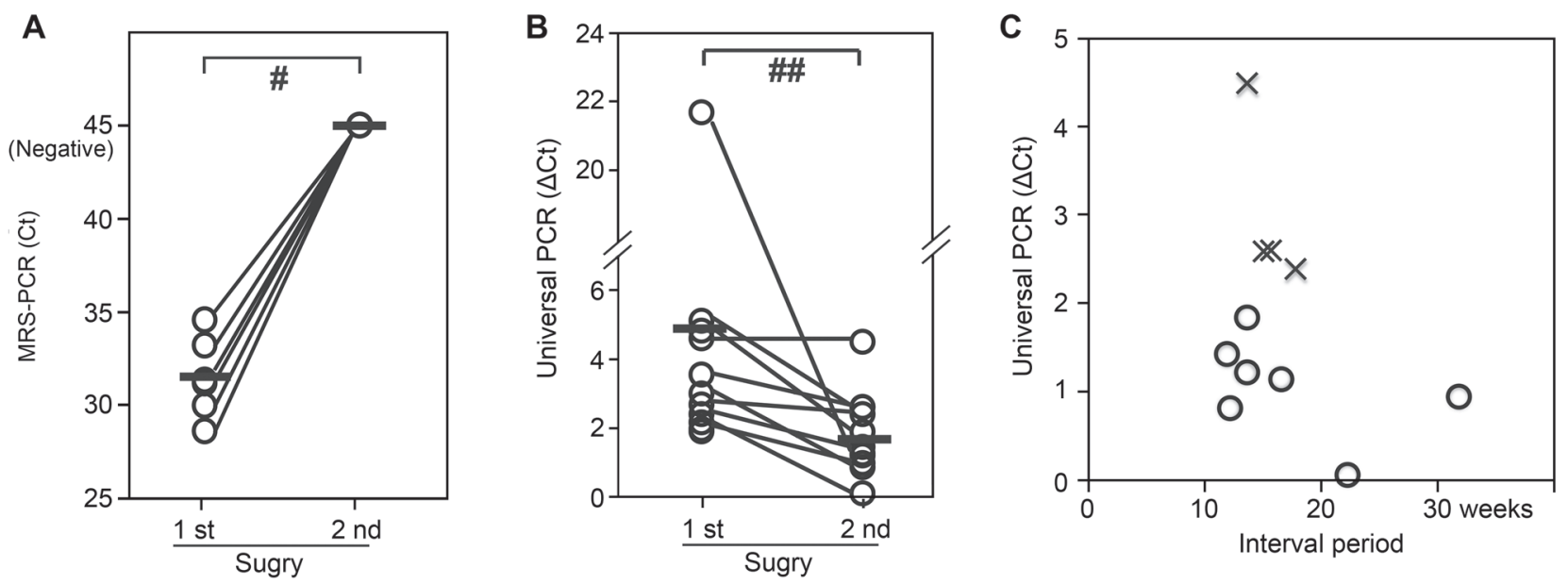

Fig. 3. Capability of real-time PCR to detect dead bacteria in patients decreased over time and lost in 20 weeks.

MRS-PCR and universal PCR were performed in samples harvested from infected hip or knee arthroplasty patients at the time of first and second surgery in successful two-stage revision surgeries. (A) MRS-PCR positive cases showed a mean Ct value of 31.4 at first surgery that becomes negative $(\mathrm{Ct}=45)$ at second surgery after mean 20.8 week interval. \#'s denotes $\mathrm{p}<0.05$ in paired test. (B) $\Delta \mathrm{Ct}$ values in universal PCR showed significant decreases from mean 4.9 to 1.8 during mean 16.5 weeks of intervals. \#\#'s denotes $\mathrm{p}<0.05$ in Wilcoxon signed ranks test. Black bars in (A) and (B) denote mean values. (C) 4 out of 11 patients showed positive in universal PCR at the time of second surgery but none of their interval periods exceeded 20 weeks. $\times$ 's denote patients with positive result and $\circ$ 's denote patients with negative result in universal PCR at the time of second surgery. 
with longer than 20 weeks of interval period, remnant bacterial DNA was not detected in both MRS-PCR and universal PCR (Figure 3-A and 3-C).

\section{Discussion}

Antibacterial treatment is sometimes initiated in patients with a strong suspicion of infection before detection of causative bacteria, although determination of the organism is important for appropriate antibacterial treatment. When bacteria are not eradicated successfully by the initial treatment, determination of the organism often becomes difficult because microbiological culture frequently shows negative results after the antibiotics (Choe et al., 2013; Ilharreborde et al., 2009; Parvizi et al., 2014; Trevors, 2012). Real-time PCR detects a part of specific bacterial DNA that enables etiological diagnosis even in this VBNC bacterial condition (Ilharreborde et al., 2009; Maas et al., 2007). However, clinical use of this novel tool as a routine examination is still controversial (Parvizi et al., 2014). One problem is its capability to detect bacterial DNA from dead bacteria and may possibly lead to a false positive result by detecting remnant bacterial DNA in successfully treated infection cases (Maas et al., 2007; McKillip et al., 1999; van der Heijden et al., 1999). Evaluation of the time duration for which real-time PCR can detect dead bacterial DNA is, therefore, of clinical importance because this helps to judge the status of bacteria in culture negative but real-time PCR positive cases for which antibacterial treatment had been initiated.

In the current study, real-time PCR based on a previously established MRS specific PCR and/or pan bacterial universal PCR (Choe et al., 2013; Choe et al., 2011; Kobayashi et al., 2006) was used to detect dead bacterial DNA from successfully treated bacteria in vitro and in clinical samples. Our in vitro study mimicked the clinical situation in which bacterial DNA remains after successful treatment. We demonstrated that the time period for which real-time PCR can detect the mecA gene from dead MRSA was less than 16 weeks and that for $16 \mathrm{~S}$ rRNA gene from both dead S.epidermidis and E.coli were less than 20 weeks. These data were in a wide range consistent with our clinical results of successfully treated arthroplasty infection cases, which demonstrated the PCR detects remnant dead bacterial DNA for several weeks but less than 20 weeks. Our in vitro study revealed that the reduction of the amount of dead bacterial DNA starts in 1 week after treatment and gradually decreases overtime. This gradual reduction suggests that the bacterial DNA was not degraded directly by the treatment, but subjected to digestion by DNases following bacterial death. Accordingly, the capability of real-time PCR for detecting dead bacterial DNA decreased over time.
In our clinical cases, all mecA genes becomes undetectable in MRS-PCR in a mean 20.8 weeks after treatment. The capacity of universal PCR for the detection of dead bacteria also decreased over time. Although universal PCR detected remnant dead bacterial DNA after treatment in 4 patients, this capacity did not last beyond 20 weeks in any case. This is likely because universal PCR is designed for pan-bacterial detection, and therefore, its capacity to detect bacterial DNA is dependent upon on the causative strain. Current in vitro data have shown that the duration of the real-time PCR detection period in treated bacterial DNA varied depending on the pathogen and treatment method i.e. alcohol-treated E. coli was detectable for a shorter period as compared with alcohol-treated S. epidermidis and in VCM-treated MRSA was detectable for a shorter period as compared with LZD-treated MRSA. These differences may be due to structural differences between gram-positive and negative strains and their mode of action (the disinfectant properties of VCM versus the bacteriostatic properties of LZD). A limitation of our in vitro study is that we only investigated three strains of bacteria. Since there are numerous other strains that cause clinical infection, the real-time PCR detectable period for strain of interest should be individually assessed. Our in vitro method to assess the dead bacterial DNA would be suitable for that purpose as a future study. Consistent results between current in vitro and clinical data indicate that the capacity of real-time PCR for the detection of dead bacteria will decrease overtime and is lost by 20 weeks after successful treatment. On the other hand, shortly after the first initiation of treatment, alive-dead discrimination assay would be required to judge the bacterial viability in culture negative but real-time PCR positive cases.

In conclusion, to properly evaluate the result of real-time PCR in patients after initiation of antibacterial treatment, the presence of DNA from dead bacteria must always be considered because real-time PCR can detect the DNA of treated bacteria for several weeks. However, the amount of dead bacterial DNA gradually decreased over time and the real-time PCR capability for detecting the dead bacterial DNA is most likely lost in 20 weeks after successful treatment.

\section{Acknowledgements}

The authors did not receive outside funding or grants in support of this research.

\section{Literature}

Choe H., Y. Aota, N. Kobayashi, Y. Nakamura, Y. Wakayama, Y. Inaba and T. Saito. 2013. Rapid sensitive molecular diagnosis of pyogenic spinal infections using MRS specific PCR and 16S rRNA gene-based universal PCR. Spine J. 14(2): 255-262

Choe H., Y. Inaba , N. Kobayashi, C. Aoki , J. Machida, N. Nakamura , S. Okuzumi and T. Saito. 2013. Use of real-time polymerase 
chain reaction for the diagnosis of infection and differentiation between gram-positive and gram-negative septic arthritis in children. J. Pediatr Orthop. 33(3): e28-33.

Ilharreborde B., P. Bidet , M. Lorrot , J. Even , P. Mariani-Kurkdjian , S. Liguori , Vitoux C., Lefevre Y., Doit C., Fitoussi F., et al. 2009. New real-time PCR-based method for Kingella kingae DNA detection: application to samples collected from 89 children with acute arthritis. J. Clin. Microbiol. 47(6): 1837-1841.

Keer J.T. and L. Birch. 2003. Molecular methods for the assessment of bacterial viability. J. Microbiol. Methods. 53(2): 175-183.

Kobayashi N., T. W. Bauer, M.J. Tuohy, I.H. Lieberman, V. Krebs, D. Togawa, T. Fujishiro and G.W. Procop. 2006. The comparison of pyrosequencing molecular Gram stain, culture, and conventional Gram stain for diagnosing orthopaedic infections. J. Orthop. Res. 24(8): 1641-1649.

Kobayashi N., Y. Inaba, H. Choe, N. Iwamoto, T. Ishida, Y. Yukizawa, C. Aoki, H. Ike and T. Saito. 2009. Rapid and sensitive detection of methicillin-resistant Staphylococcus periprosthetic infections using real-time polymerase chain reaction. Diagn. Microbiol. Infect. Dis. 64(2): 172-176.

Lonner J.H., P. Desai, P.E. Dicesare, G. Steiner and J.D. Zuckerman. 1996. The reliability of analysis of intraoperative frozen sections for identifying active infection during revision hip or knee arthroplasty. J. Bone Joint Surg. Am. 78(10): 1553-1558.

Maas K.S., M. Mendez, M. Zavaleta, J. Manrique, M.P. Franco, M. Mulder, N. Bonifacio, M.L. Castaneda, J. Chacaltana, E. Yagui, et al. 2007. Evaluation of brucellosis by PCR and persistence after treatment in patients returning to the hospital for follow-up. Am. J. Trop. Med. Hyg. 76(4): 698-702.

McKillip J.L., L.A. Jaykus and M. Drake. 1999. Nucleic acid persistence in heat-killed Escherichia coli O157:H7 from contaminated skim milk. J. Food Prot. 62(8): 839-844.

Miyamae Y., Y. Inaba, N. Kobayashi, H. Choe, H. Ike, T. Momose, S. Fujiwara and T. Saito. 2012. Quantitative evaluation of periprosthetic infection by real-time polymerase chain reaction: a comparison with conventional methods. Diagn. Microbiol. Infect. Dis. 74(2): $125-130$.
Moojen D.J., G. van Hellemondt, H.C.Vogely, B.J. Burger, G.H. Walenkamp, N.J. Tulp, B.W. Schreurs, F.R. de Meulemeester, C.S. Schot, I. van de Pol, et al. 2010. Incidence of low-grade infection in aseptic loosening of total hip arthroplasty. Acta Orthop. 81(6): 667-673.

Morre S.A., P.T. Sillekens, M.V. Jacobs, S. de Blok, J.M. Ossewaarde, P. van Aarle, van Gemen B., J.M. Walboomers, C.J. Meijer and A.J. van den Brule. 1998. Monitoring of Chlamydia trachomatis infections after antibiotic treatment using RNA detection by nucleic acid sequence based amplification. Mol. Pathol. 51(3): 149-154.

Nilsson A.C., P. Bjorkman and K. Persson. 2008. Polymerase chain reaction is superior to serology for the diagnosis of acute $\mathrm{Myco}$ plasma pneumoniae infection and reveals a high rate of persistent infection. BMC Microbiol. 8: 93.

Parvizi J., O.F. Erkocak, C.J. Della Valle. 2014. Culture-negative periprosthetic joint infection. J. Bone Joint Surg. Am. 96(5): 430-436. Sanzen L. and A.S. Carlsson. 1989. The diagnostic value of C-reactive protein in infected total hip arthroplasties. J. Bone Joint Surg. Br. 71(4): 638-641.

Trevors J.T. 2011. Viable but non-culturable (VBNC) bacteria: Gene expression in planktonic and biofilm cells. J. Microbiol. Methods. 86(2): 266-273.

Trevors J.T. 2012. Can dead bacterial cells be defined and are genes expressed after cell death? J. Microbiol. Methods. 90(1): 25-28.

Tsaras G, A. Maduka-Ezeh, C.Y. Inwards, T. Mabry, P.J. Erwin, M.H. Murad, V.M. Montori, C.P. West, D.R. Osmon and E.F. Berbari. 2012. Utility of intraoperative frozen section histopathology in the diagnosis of periprosthetic joint infection: a systematic review and meta-analysis. J. Bone Joint Surg Am. 94(18): 1700-1611.

Van der Heijden I.M., B. Wilbrink, A.E. Vije, L.M. Schouls, F.C. Breedveld and P.P. Tak. 1999. Detection of bacterial DNA in serial synovial samples obtained during antibiotic treatment from patients with septic arthritis. Arthritis Rheum. 42(10): 2198-2203. Workowski K.A., M.F. Lampe, K.G. Wong, M.B.Watts and W.E. Stamm. 1993. Long-term eradication of Chlamydia trachomatis genital infection after antimicrobial therapy. Evidence against persistent infection. JAMA 270(17): 2071-2075. 